\title{
The use of vacuum-assisted closure in Fournier's gangrene
}

\author{
Özer Özlü${ }^{1}$, Abdulkadir Başaran${ }^{1}$, Feyzi Kurt ${ }^{2} \odot$ \\ ${ }^{1}$ Department of General Surgery, Adana City Training and Research Hospital, Adana, Turkey \\ ${ }^{2}$ Department of General Surgery, Seyhan State Hospital, Adana, Turkey
}

\begin{abstract}
Objectives: Fournier's gangrene is an emergency surgical disease which develops and progresses rapidly and there is high risk of mortality with a delay in diagnosis and treatment. The objective of this study is to investigate the impact of vacuum-assisted closure on the clinical outcome in the treatment of Fournier's gangrene.

Methods: A total of 28 patients diagnosed as Fournier's gangrene and admitted to our hospital from January 2010 to December 2018 are included in this retrospective study. The diagnosis was established on the basis of physical examination. Epidemiological data including gender, age, and presence of diabetes mellitus, clinical outcomes including use of vacuum-assisted closure, length of admittance, the number of debridement and other surgical procedures were evaluated retrospectively from the medical records and the hospital treatment registry.

Results: There were $16(57.1 \%)$ male and $12(42.9 \%)$ female patients and the mean age of the patients was $59.54 \pm 16.76$ years. The mean number of debridement was $3.67 \pm 1.5$ times and the total hospital stay was $26.67 \pm 7.7$ days for vacuum-assisted closure group $(n=9)$. The average number of debridement was $4.11 \pm$ 0.94 times and the total hospital stay was $31.58 \pm 6.33$ days for the rest of the patients $(n=19)$.

Conclusions: The average number of debridement and hospital stay were lower in patients treated with vacuum-assisted closure. We also observed an increase in patient comfort and the workload of the stuff is decreased as there was less exudate in the vacuum-assisted closure group.

Keywords: Fournier's gangrene, vacuum-assisted closure, diabetes, hospital stay
\end{abstract}

$\mathrm{F}$ ournier's gangrene (FG) is an emergency surgical disease that quickly develops and progresses. There is high risk of mortality with a delay in diagnosis and treatment. FG is an obliterating endarteritis of the subcutaneous arteries resulting with gangrene and fasciitis of the external genitalia. Although FG often involves genital and perianal region, it can also be seen in lower extremities and other parts of the body. The disease was named after Jean Alfred Fournier who was the first to describe it [1]. However several sources state that the disease was first described by Bauriene in 1764 [2, 3]. Fournier's disease is defined as a gangrene that has a fulminant course in specific focus of scrotum. Most of these infections were initially divided into subgroups such as necrotizing fasciitis, clostridial gangrene, and streptococcal gangrene. FG was then defined as scrotal gangrene, periurethral flegman, or synergistic necrotizing cellulitis [3, 4].

The disease affects mostly men. However, it is also observed in women and children. FG often occurs in 
colorectal $(30-50 \%)$ or urogenital $(20-40 \%)$ regions and other areas of skin (20\%) [3]. FG is more often seen with several systematic diseases. $20-70 \%$ of patients have diabetes mellitus (DM) [5]. The primary cause for development of disease is the reduced cellular immunity. Any condition reducing cellular immunity may lead to development of FG. The bacterial infections observed in anorectal, perianal and genitourinary regions thrombose small subcutaneous veins, resulting in development of gangrene in the skin. The bacteria found in those regions usually causes rapid and severe tissue damage. In case of local trauma or infection the high virulence causes the disease to develop. FG is a polymicrobial disease that often develops with aerobic and anaerobic microorganisms [4].

The treatment of disease includes aggressive surgical debridement in combination with the use of broad spectrum antibiotics [6]. Despite advances in treatment, the mortality and morbidity of the disease remains still high [7]. There are different methods attempted to reduce morbidity and mortality of this disease. The Vacuum-Assisted Closure (VAC) is one of these methods. The objective of this study is to review the efficacy of VAC on the clinical outcomes of patients with FG. VAC covers the wound with a foam dressing and mechanically brings the skin edges closer by applying negative pressure to the wound bed. The formation of micro-deformation in the tissue and the increase in the capillary flow stimulates the formation of granulation tissue. The removal of wound exudate and its enzymes prevents further tissue damage and reduces the wound dressing changes by keeping the surrounding skin dry [8].

\section{METHODS}

\section{Study Design and Participants}

The data of 28 patients diagnosed as Fournier's gangrene and admitted to our hospital between January 2010 and December 2018 were reviewed retrospectively. This study was approved by the local Clinical Research Ethical Committee of the Training and Research Hospital in our city (Decision no: 490/2019). Written informed consent was obtained from a patient for imaging the lesions.

\section{Treatment}

The diagnosis was established based on physical examination (Fig. 1a). Surgical debridement was performed as soon as possible. The patients received double parenteral antibiotics until the culture and sensitivity results were available. The wound dressings were changed daily and the surgical debridement was performed depending on the nature of the wound and necrosis as the standard procedure. After the acute phase VAC was used in some patients mainly depending on extension of the necrosis and presence of DM. The use of VAC device (Renasys EZ Max, Smith and Nephew Inc., St. Petersburg, Florida, USA) starts with placing foam-based sponges with small pores on the wound. Suction tubing is then placed on top of the sponge and the area is sealed with adhesive tapes (Fig. $1 b)$. The tube is connected to the vacuum pump and a pressure between $80-120 \mathrm{~mm}$ is applied [9]. The dressing was changed every 48-72 hours depending on the amount of exudate. The closure of the wound or the continuation of VAC therapy was decided by the formation of granulation tissue, the presence of exudate or necrotic tissue in the wound (Fig. 1c).
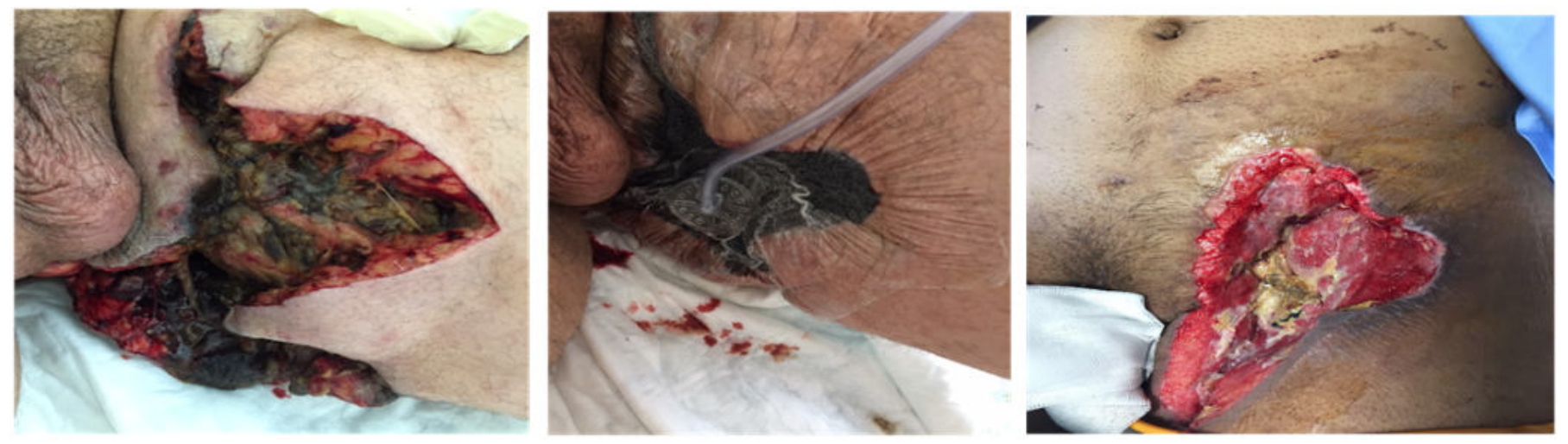

Fig. 1. a) Fournier's gangrene, b) Application of VAC, c) The wound after one week 
Table 1. Demographic and clinical data of patients based on treatment

\begin{tabular}{lccc}
\hline & $\begin{array}{c}\text { Group 1 } \\
(\mathbf{n = 9 )}\end{array}$ & $\begin{array}{c}\text { Group 2 } \\
(\mathbf{n = 1 9 )}\end{array}$ & p value \\
\hline Gender (M/F) & $5 / 4$ & $11 / 8$ & \\
Age & $65.0 \pm 17.8$ & $56.95 \pm 16.1$ & 0.054 \\
DM (-/+) & $1 / 8$ & $13 / 6$ & $\mathbf{0 . 0 1}$ \\
Lesion size (cm) & $24.4(12-44.5)$ & $22.6(10-42)$ & 0.825 \\
Debridement & $3.67 \pm 1.5$ & $4.11 \pm 0.94$ & 0.48 \\
Hospital Stay (days) & $26.67 \pm 7.7$ & $31.58 \pm 6.3$ & 0.114 \\
\hline
\end{tabular}

Data are shown as mean \pm standard deviation or number. M/F: Male/Female

\section{Data collection}

Epidemiological data including gender, age and presence of diabetes mellitus, clinical outcomes including use of vacuum-assisted closure, length of admittance, the number of debridement and other surgical procedures were evaluated from the medical records and the hospital treatment registry.

\section{Statistical Analysis}

The data were analyzed using SPSS (Statistical Package for Social Sciences) 20.0 for Windows. The distribution of the variables was checked with normality tests. The t-test was used for normally distributed continuous variables, and Mann-Whitney U Test was used for non-normally distributed variables. The results were expressed in \pm standard deviation, $\mathrm{n}$, and percent (\%). A $p$ value of $<0.05$ was considered statistically significant.

\section{RESULTS}

A total of 28 patients were included in the study. Sixteen $(57.1 \%)$ patients were males and 12 (42.9\%) patients were females. The mean age of the patients was $59.54 \pm 16.76$ years (27-78 years). There were 14
$(50 \%)$ patients with DM and $8(57.15 \%)$ of them were females and $6(42.85 \%)$ of them were males. The mean number of debridement was $3.96 \pm 1.14$ (2-7) and the total hospital stay was $30.0 \pm 7.05$ (15-39) days.

Further analyses were performed according to groups based on treatment as; group $1=\mathrm{VAC}$ group, group $2=$ conservative treatment group. In group 1 $55.55 \%$ of patients were male $(n=5)$ and $44.44 \%(n$ $=4$ ) were female. The mean number of debridement was $3.67 \pm 1.5$ and the total hospital stay was $26.67 \pm$ 7.7 days for group $1(\mathrm{n}=9)$. The average number of debridement was $4.11 \pm 0.94$ and the total hospital stay was $31.58 \pm 6.33$ days for group $2(n=19)$. The difference between these groups was not statistically significant. The demographic and clinical data of treatment groups are summarized in Table 1.

Half of the patients $(n=14)$ had DM. For the patients with DM the mean number of debridement and the duration of hospital stay were higher than the patients who did not have DM but the difference between the groups was not statistically significant. The data concerning DM is summarized in Table 2.

In group 1 secondary wound healing was achieved in 7 patients. Whereas one patient healed with a flap and the other one with skin grafting. In group 1 there

Table 2. Data of patients based on presence of diabetes

\begin{tabular}{lccc}
\hline & DM (+) & DM (-) & p value \\
\hline Gender (M/F) & $6 / 8$ & $10 / 4$ & \\
Age & $61.9 \pm 14.9$ & $57.2 \pm 18.7$ & 0.58 \\
Debridement & $3.93 \pm 1.27$ & $4.0 \pm 1.04$ & 0.73 \\
Hospital stay & $31.07 \pm 7.93$ & $28.93 \pm 6.16$ & 0.231 \\
\hline
\end{tabular}

Data are shown as mean \pm standard deviation or number. M/F: Male/Female 
Table 3. Clinical outcomes of patients

\begin{tabular}{lcc}
\hline & $\begin{array}{c}\text { Group 1 } \\
(\mathbf{n = 9 )}\end{array}$ & $\begin{array}{c}\text { Group 2 } \\
(\mathbf{n = 1 9 )}\end{array}$ \\
\hline Secondary healing, n (\%) & $7(77.8)$ & $11(57.9)$ \\
Flap, n (\%) & $1(11.1)$ & $4(21.05)$ \\
\hline Skin graft, n (\%) & $1(11.1)$ & $4(21.05)$ \\
Colostomy, n (\%) & $0(0)$ & $2(10.5)$ \\
\hline Mortality, n (\%) & $0(0)$ & $1(5.26)$ \\
\hline
\end{tabular}

was no mortality and none of the patients underwent colostomy. Whereas in group 2 two patients underwent colostomy and one patient died due to sepsis and multiple organ failure. The kind of healing and the clinical outcomes are summarized in Table 3.

There was no problem with the flap and graft performed in group 1 but in group 2 local necrosis was developed in one flap. The necrotic area was healed after the debridement and the wound is closed with fibrosis.

\section{DISCUSSION}

The earlier the diagnosis of FG is established and treated, the better the prognosis is. The radiological methods, such as ultrasonography, computed tomography, and magnetic resonance imaging can be used for diagnosis. However, the primary diagnosis of FG is based on the findings of physical examination [7, 10]. The signs of inflammation, presence of edema, necrosis, subcutaneous crepitation and pain are important for diagnosis. We also established the diagnosis on the basis of physical examination findings. Although the FG is seen in both genders and at any age, it mostly affects elderly men [11-13]. Most of the patients in our study were also elderly men. The reason for high incidence of FG in elderly is that a number of chronic diseases are common at older ages. Other than older age, obesity, DM, alcoholism, respiratory system diseases, diseases of liver, malnutrition, and other immunosuppressive diseases play a role in development of FG $[14,15]$. DM is the most critical and common disease among these conditions with an incidence of $70 \%$ in the literature $[16,17]$. In our study $50 \%$ of the patients had diabetes mellitus.

FG is more common in the perineal, urogenital and anorectal regions. However, it can be seen in other parts of the body including abdomen and lower extremities. It can also be observed in perineum of women during postpartum period $[5,13]$. All of our patients had FG at the perineal, urogenital or anorectal regions. The treatment of FG includes broad aggressive surgical debridement and use of appropriate broad spectrum antibiotics [7, 18]. During the debridement, the entire necrotic tissue must be removed until the living tissue is reached. The debridement must be repeated until the infection is controlled. The mean number of debridement ranges from 3 to 7 for each patient in the literature [19]. The mean number of debridement was 2-7 (3.96 \pm 1.14$)$ and the total hospital stay was $30.0 \pm 7.05$ (15-39) days in our study. The duration of hospital stay was $31.07 \pm 7.93$ days for patients with DM and $28.93 \pm 6.16$ days for rest of the patients and the difference between the groups was not statistically significant. The mean number of debridement and the total hospital stay was less in group $1 \mathrm{com}-$ pared to group 2 and the difference between the groups was also not statistically significant. There were more patients with DM in group $1(88.9 \%$ to $31.6 \%)$ and the difference between the groups was statistically significant $(p=0.01)$. The patients in group 1 were also older and the lesion size was bigger. In a randomized study a significant difference could be observed considering above mentioned conditions.

The Negative Pressure Wound Treatment (NPWT) is based on continuous or intermittent application of negative pressure on the wound surface to remove the fluid material from the wound site and we know that NPWT has been used for decades. Today, advanced systems have been developed for NPWT with the use of technology. Recently, the VAC has been widely used for the pressure sores in particular and its use for patients with chronic wound increased as well. The need for debridement of patients is reduced with the use of VAC [20]. This also improves the comfort of patients and decreases the work load of healthcare provider. Shorter duration of hospital stay is also reported $[21,22]$. The patients become more eligible for flap or grafting sooner $[23,24]$. The costs are lower considering the number of debridement and the duration of hospital stay [25]. When VAC is used for eligible patients, the need for opening stoma is also reduced [26]. This has positive effects on the psychosocial condition of patients $[20,21,27]$. The inci- 
dence for development of infections will be reduced as a confined environment is created with VAC. However, there are no relevant randomized studies in the literature.

VAC is supplementary in treatment of FG and the gold standard for its treatment is broad aggressive surgical wound debridement in combination with appropriate antibiotics. The treatment of FG is a process that requires multidisciplinary approach. The use of VAC creates granulation tissue earlier in the wound [28]. Therefore, the closure of the wounds of the patients occurs faster and can be healed easily with flap or skin graft operations. Appropriately secondary wound healing was provided in $77.8 \%$ of patients in the VAC group. However $57.9 \%$ of the patients in group 2 had secondary wound healing. Flap and graft necrosis was observed in group 2 while no complication was observed in the VAC group.

\section{Limitations}

Our limitations are the retrospective nature of the study and the relatively small number of patients. Prospective randomized controlled trials are needed with more patients.

\section{CONCLUSION}

Vacuum-Assisted Closure is a negative pressure treatment method based on the removal of liquid material from the wound by applying negative pressure to the wound surface intermittently or continuously. The number of debridement and hospital stay were lower in FG patients who were treated with applying VAC in our study. Also secondary wound healing was better and there was no loss of flap and skin grafts. We observed that using VAC is effective in diabetic patients with FG. In addition we observed an increase in patient comfort and the workload of the health care stuff is decreased.

\section{Authors' Contribution}

Study Conception: ÖÖ, AB, FK; Study Design: ÖÖ, AB, FK; Supervision: ÖÖ, AB, FK; Funding: ÖÖ, AB; Materials: ÖÖ, FK; Data Collection and/or Processing: ÖÖ, FK; Statistical Analysis and/or Data Interpretation: ÖÖ, AB; Literature Review: ÖÖ, AB; Manuscript Preparation: ÖÖ, AB, FK and Critical Re- view: ÖÖ, AB.

\section{Conflict of interest}

The authors disclosed no conflict of interest during the preparation or publication of this manuscript.

\section{Financing}

The authors disclosed that they did not receive any grant during conduction or writing of this study.

\section{REFERENCES}

1. Fournier JA. Gangrene foudroyante de la verge. Med Pract 1883;4:589-97.

2. Eke N. Fournier`s gangrene: a review of 1726 cases. Br J Surg 2000;87:718-28.

3. Thwaini A, Khan A, Malik A, Cherian J, Barua J, I Shergill I, et al. Fournier`s gangrene and its emergency management. Postgrad Med J 2006;82:516-9.

4. Czymek R, Schmidt A, Eckmann C, Bouchard R, Wulff B, Laubert T, et al. Fournier's gangrene: vacuum assisted closure versus conventional dressing. Am J Surg 2009;187:168-76.

5. Morpurgo E. Galandiuk S. Fournier`s gangrene. Surg Clin N Am 2002;82:1213-24.

6. Yanar H. Taviloglu K. Ertekin C, Guloglu R, Zorba U, Cabioglu N, et al. Fournier`s gangrene: risk factors and strategies for management. Word J Surg 2006;30:1750-4.

7. Furr J, Watts T, Street R, Cross B, Slobodov G, Patel S. Contemporary trends in the inpatient management of Fournier's gangrene: predictors of length of stay and mortality based on population-based sample. Urology 2016;102:79-84.

8. Angelis S, Apostolopoulos AP, Kosmas L, Balfousias T, Papanikolaou A. The use of vacuum closure-assisted device in the management of compound lower limb fractures with massive soft tissue damage. Cureus 2019;11:e5104.

9. Morykwas MJ, Simpson J, Punger K, Argenta A, Kremers L, Argenta J: Vacuum-assisted

closure: state of basic research and physiologic foundation. Plast Reconstr Surg 2006;117:121-6.

10. Oguz A, Gumus M, Turkoglu A, Bozdag Z, Ulger BV, Agacayak E, et al. Fournier's gangrene: a summary of 10 years of clinical experience. Int Surg 2015;5:934-41.

11. Heiner JD, Baldwin K, Laselle B. Fournier gangrene: rapid diagnosis with bedside ultrasonography. CJEM 2010;12:528-9.

12. Erdogan A, Aydogan I, Senol K, Uckan EM, Ersoz S, Tez M. Simple scoring system for prediction of mortality in Fournier `s gangrene. Eur J Trauma Emerg Surg 2016;42:513-8.

13. Korkut M, Icoz G, Dayangac M, Akgun E, Yeniay L, Erdogan $\mathrm{O}$, et al. Outcome analysis in patients with Fournier's gangrene: report of 45 cases. Dis Colon Rectum 2003;46:649-52.

14. Norton KS, Johnson LW, Perry T, Perry KH, Sehon JK, Zibari GB. Management of Fournier's gangrene: an eleven year retrospective analysis of early recognition, diagnosis, and treatment. Am Surg 2002;68:709-13. 
15. Canbaz H, Caglikulekci M, Altun U, Dirlik M, Turkmenoglu $\mathrm{O}$, Tasdelen B, et al. Fournier's gangrene : analysis of risk factors affecting the prognosis and cost of therapy in 18 cases. Ulus Travma Acil Cerrahi Derg 2010;16:71-6.

16. Yilmazlar T, Isık O, Ozturk E, Ozer A, Gulcu B, Ercan I. Fournier's gangrene: Review of 120 patients and predictors of mortality. Ulus Travma Acil Cerrahi Derg 2014;20:333-7.

17. Mallikarjuna MN, Vijayakumar A, Patil VS, Shivswamy BS. Fournier's gangrene: current practices. ISRN Surg 2012:2012:942437.

18. Smith GL, Bunker CB, Dinneen MD. Fournier`s gangrene. Br J Urol 1998;81:347-55.

19. Benjelloun EB, Souiki T, Yakla N, Ousadden A, Mazaz K, Louchi A, et al. Fournier's gangrene: our experience with 50 patients and analysis of factors affecting mortality. World J Emerg Surg 2013;8:13.

20. Assenza M, Cozza V, Sacco E, Clementi I, Tarantino B, Passafiume F, et al. VAC treatment in Fournier's gangrene: personal experience and literature review. Clin Ter 2011:162:e1-5.

21. Cuccia G, Mucciardi G, Morgia G, d'Alcontres FS, Gali A, Cotrufo S, et al. Vacuum-assisted closure for the treatment of Fournier's gangrene. Urol Int 2009;82:426-31.

22. Durmish Y, Gervaz P, Bühler L, Bucher P, Zufferey G, Al-
Mazrouei A, et al. Vacuum -assisted closure: its role in the treatment of complex abdominal and perineal wounds. J Chir 2007:144:209-13.

23. Ugur M, Oruc C, Y1ldiz I, Koca YS, Daban U. The role of co-administration of damage control surgery and vacuum-assisted closure in the treatment of perineal wounds. Turk J Surg 2018;34:229-30.

24. Lohsiriwat V. Persistent perineal sinus: incidence, pathogenesis, risk factors and management. Surg Today 2009;39:189-93. 25. Liu Z, Dumville JC, Hinchliffe RJ, Cullum N, Game F, Stubbs N, et al. Negative pressure wound therapy for treating foot wounds in people with diabetes mellitus. Cochrane Database Syst Rev 2018;10:CD010318.

26. Yucel M, Ozpek A, Basak F, Kilic A, Unal E, Yuksekdag S, et al. Fournier's gangrene: a retrospective analysis of 25 patients. Ulus Travma Acil Cerrahi Derg 2017;23:400-4.

27. Wagner S, Greco F, Hoda MR, Kawan F, Heynemann H, Fornara P. Is intensive multimodality therapy the best treatment for Fournier gangrene? Evaluation of clinical outcome and survival rate of 41 patients. Surg Infect (Larchmt) 2011;12:379-83. 28. Chennamsetty A, Khourdaji I, Burks F, Killinger KA. Contemporary diagnosis and management of Fournier's gangrene. Ther Adv Urol 2015;7:203-15. 